\title{
Association between exposure-relevant polymorphisms in CYP1B1, EPHX1, NQO1, GSTM1, GSTP1 and GSTT1 and risk of colorectal cancer in a Czech population
}

\author{
IVONA HLAVATA ${ }^{1,2}$, DAVID VRANA $^{1,3,5}$, ZDENEK SMERHOVSKY $^{1,6}$, \\ BARBARA PARDINI $^{7}$, ALESSIO NACCARATI $^{7}$, PAVEL VODICKA $^{7}$, JAN NOVOTNY $^{4}$, \\ BEATRICE MOHELNIKOVA-DUCHONOVA ${ }^{1,3}$ and PAVEL SOUCEK ${ }^{1}$
}

\author{
${ }^{1}$ Toxicogenomics Unit, National Institute of Public Health, Srobarova 48, 10042 Prague; \\ ${ }^{2}$ Third Faculty of Medicine, Charles University in Prague, Ruska 87, 10000 Prague; ${ }^{3}$ First Faculty of Medicine, and \\ ${ }^{4}$ Department of Oncology, General Teaching Hospital and First Faculty of Medicine, Charles University in Prague, \\ Katerinska 32, 12108 Prague; ${ }^{5}$ Department of Medicine, Hospital Atlas, Tomase Bati 5135, 76001 Zlin; \\ ${ }^{6}$ Institute of Epidemiology, Second Faculty of Medicine, Charles University in Prague, V Uvalu 84, 15006 \\ Prague; ${ }^{7}$ Department of Molecular Biology of Cancer, Institute of Experimental Medicine, \\ Academy of Sciences of Czech Republic, Videnska 1083, 14220 Prague, Czech Republic
}

Received June 9, 2010; Accepted July 30, 2010

DOI: 10.3892/or_00000992

\begin{abstract}
Associations of functional single nucleotide polymorphisms in cytochrome P450 1B1, epoxide hydrolase 1, $\mathrm{NAD}(\mathrm{P}) \mathrm{H}$ :quinone oxidoreductase 1, glutathione S-transferase Pi-1 and deletions of glutathione S-transferases Mu-1 and $\theta-1$ with colorectal cancer risk were investigated in a hospital-based case-control study on 495 matched pairs of Czech Caucasians. Polymorphisms were assessed by polymerase chain reaction restriction fragment length polymorphism-based methods, allele-specific multiplex and allelic discrimination by real-time polymerase chain reaction. Carriers of variant Ser allele in codon 453 of cytochrome P450 1B1 (rs1800440) were at a significantly lower risk of colorectal cancer compared to carriers of the wild-type allele (adjusted odds ratio, $\mathrm{aOR}=0.68, \mathrm{CI}=0.51-0.89, \mathrm{p}=0.006$ ). The combination of polymorphisms in codons 453 and 432 (rs1056836) of cytochrome P450 1B1 further increased the protective effect $(\mathrm{aOR}=0.53, \mathrm{CI}=0.34-0.83, \mathrm{p}=0.005)$. The glutathione S-transferase $\mathrm{Mu}-1$ deletion was associated with a moderately elevated colorectal cancer risk $(\mathrm{aOR}=1.30$, $\mathrm{CI}=1.01-1.68, \mathrm{p}=0.044)$. Combination of glutathione $\mathrm{S}$ transferase $\mathrm{Mu}-1$ and $\theta-1$ deletion was associated with a significantly higher colorectal cancer risk compared to the presence of both full-length genes $(\mathrm{aOR}=1.58, \mathrm{CI}=1.01-2.47$, $\mathrm{p}=0.044)$. Genetic polymorphisms in glutathione $\mathrm{S}$ -
\end{abstract}

Correspondence to: Dr Pavel Soucek, Toxicogenomics Unit, National Institute of Public Health, Srobarova 48, Prague 100 42, Czech Republic

E-mail: psoucek@szu.cz

Key words: colorectal cancer, cytochrome P450, glutathione Stransferase, polymorphism, risk transferase Pi-1, NAD(P)H:quinone oxidoreductase 1, epoxide hydrolase 1 and deduced epoxid hydrolase 1 activity did not modify the risk of colorectal cancer. These results provide further evidence that interaction between metabolic gene variants contributes to colorectal carcinogenesis.

\section{Introduction}

Worldwide, colorectal cancer (CRC) is the third most common cancer with an estimated 1,023,256 newly diagnosed cases and 529,020 deaths per year (1). In terms of CRC incidence, the Czech Republic ranks second in Europe (2) and the number of new cases is rapidly increasing (3). It is postulated that $20-30 \%$ of all patients with CRC have a family history of CRC that suggests a genetic contribution, common exposures among family members, or a combination of both (4). Red meat consumption has frequently shown an association with an increased risk of CRC. It has been proposed that this risk may be due to carcinogenic polycyclic aromatic hydrocarbons (PAHs) and heterocyclic amines produced when meat is cooked at high temperatures (5). These chemicals, aromatic amines and nitroso compounds may be found in tobacco smoke which is also recognized as a potential CRC risk factor (6). Metabolism of these chemicals is performed by the genetically variable xenobiotic-metabolizing enzymes (XME). Briefly, phase I XME such as cytochromes P450 (e.g. CYP1B1), epoxide hydroxylases (e.g. EPHX1) or oxidoreductases (e.g. NQO1) produce reactive metabolites which are then conjugated by transferases (e.g. GSTM1, GSTP1, GSTT1) to polar compounds in phase II reactions. Phase II metabolites may be further processed (metabolism, cleavage, hydrolysis, acetylation, etc.) by phase III XME (7). Genetic polymorphisms in XME genes that alter the expression and activity of the protein products are thus strong candidates for CRC risk modifiers. 
Cytochromes P450 (CYPs) are the most important enzymes involved in the phase I of biotransformation. CYPs catalyze a large number of reactions modifying dietary and smoking-derived pre-carcinogens and participate in the metabolism of endogenous compounds including hormones and bile acids (8). CYP1B1 plays an important role in activating PAHs or heterocyclic amines to reactive metabolites that cause DNA damage. Polymorphisms in CYP1B1 have recently been associated with CRC susceptibility (9). Epoxide hydrolase (EPHX1) catalyzes the hydrolysis of major metabolites of PAHs (epoxides) to less reactive trans-dihydrodiols. Two common alleles of EPHX1 in codons 113 (site T337C, amino acid change Tyr113His, dbSNP: rs 1051740) and 139 (A415G, His139Arg, rs2234922) affect enzyme activity (10). However, a lack of association of EPHX1 polymorphisms with $\mathrm{CRC}$ risk has been reported $(11,12)$. NAD $(\mathrm{P}) \mathrm{H}$ :quinone oxidoreductase (NQO1) is an obligate two-electron reductase that can either bioactivate or detoxify quinones and may play an important role in chemoprevention (13). An NQOI polymorphism in codon 187 (C609T, Pro187Ser, rs1800566), resulting in an inactive enzyme, has been associated with the risk of CRC $(12,14)$ and sporadic distal colorectal adenomas (15). Glutathione S-transferases (GST), GSTM1, GSTP1 and GSTT1 belong to the most frequently studied XMEs in molecular epidemiology of cancer. Large genomic deletions (null genotype) of GSTM1 and GSTT1 result in a complete lack of enzyme activities. A GSTP1 polymorphism in codon 105 (A313G, Ile105Val, rs1695) generates an enzyme with different heat stability and substrate affinity (16). A study by Ferraz et al (17) suggested that GSTT1 and GSTP1 could play a role in the occurrence of KRAS and TP53 mutations in CRC and a report by Moore et al (18) showed associations between colorectal adenomas and GSTM1-plus and GSTT1null among smokers. Recently, we have reported an association of combined EPHX1, GSTM1 and GSTT1 polymorphisms with genetic damage (higher DNA single-strand breaks) in general Czech population (19).

This study evaluated associations between polymorphisms in CYP1B1, EPHX1, NQO1, GSTM1, GSTP1, GSTT1 and risk of $\mathrm{CRC}$ in a relatively homogeneous population with one of the highest CRC incidences.

\section{Materials and methods}

Subjects. The study population comprised 495 patients with CRC (cases) and 495 individuals with no evidence of colorectal malignancy (controls). Eligibility criteria for study participation of cases and controls included Czech origin, ages 29 years or more, and consent to provide biological samples for genetic analysis. To reduce selection bias, only those subjects with no previous diagnosis were included in the study to avoid inclusion of patients with chronic diseases who may be repeatedly admitted to hospital and modify their habits because of their disease. Recruitment of participants was coordinated by Department of Oncology, General Teaching Hospital in Prague in the period between September 2004 and February 2006. Cases with histologically-confirmed positively-diagnosed CRC were recruited from patients visiting nine oncology departments (two in Prague, one in Benesov, Brno, Liberec, Ples, Pribram, Usti nad Labem and Zlin). The participating hospitals are located throughout the Czech Republic; therefore, it is reasonable to expect, that the cases represent the general Czech population. During the study period, a total of 968 CRC cases provided consent to participate in the study. Of the recruited group, 16 cases met the Amsterdam criteria I and II for hereditary CRC and were excluded from the study (20). Four hundred and fifty-seven cases were excluded because eligibility criteria were not met or incomplete lifestyle and potential risk factor information was available or biological material was lacking.

Controls were recruited over the same period as the cases from individuals undergoing colonoscopy for various gastrointestinal complaints (macroscopic bleeding, positive fecal occult blood test, hemorrhoids, abdominal pain of unknown origin) from five large gastroenterological departments (Prague, Brno, Jihlava, Liberec, and Pribram). Due to the high incidence of CRC in the Czech Republic, colonoscopy is highly recommended and widely practiced. Controls were selected from those showing negative colonoscopy results for malignancy or idiopathic bowel diseases. Controls had no diagnosis of chronic disease necessitating repeated admittance to hospital (21). One hundred and ninety-three controls were excluded because eligibility criteria were not met or incomplete lifestyle and potential risk factor information was available or biological material was lacking. In the last step, controls were matched on the basis of age $( \pm 2.5$ years $)$ to cases and thus 495 case-control pairs were established for this study. Study subjects provided by self-guided questionnaire information on their education, living area, lifestyle habits, body mass index (BMI), diabetes, family/personal history of cancer and long-term (at least 6 consecutive months) drug use. The case-control set was not collected specifically for the present study, but for previous studies on the risk of genetic polymorphisms in different pathways, as recently described (21).

All subjects were informed and gave written consent to participate in the study. The design of the study was approved by the Ethics Committee of the Institute of Experimental Medicine, Prague, Czech Republic.

Genotyping. Blood was collected during diagnostic procedures using tubes with $\mathrm{K}_{3}$ EDTA anticoagulant. DNA was isolated from lymphocytes using the phenol/chloroform extraction method as described earlier (22). Polymorphisms in CYP1B1 (Leu432Val, dbSNP: rs1056836 and Asn453Ser, rs1800440), GSTM1 (gene deletion) and GSTT1 (gene deletion) were assayed by published methods: polymerase chain reaction (PCR) restriction fragment length polymorphism and allelespecific multiplex PCR (23). Oligonucleotide primers were synthesized by Generi Biotech (Hradec Kralove, Czech Republic). Polymorphisms in GSTP1 (Ile105Val, rs1695), NQO1 (Pro187Ser, rs1800566) and EPHX1 (His113Tyr, rs 1051740 and Arg139His, rs2234922) were assayed by allelic discrimination with TaqMan Drug Metabolism Genotyping Assays (Applied Biosystems, Foster City, CA) using real time PCR in RotorGene 6000 (Corbett Research, Brisbane, Australia). The TaqMan assays (GSTP1, Ile105Val, C-3237198_20; NQO1, Pro187Ser, C-2091255_30; EPHX1, His113Tyr, C-14938_30 and Arg139His, C-11638783_30) were performed according to manufacturer's instructions 
Table I. Characteristics of the studied population.

\begin{tabular}{|c|c|c|c|c|c|}
\hline & Cases & Controls & $\mathrm{cOR}^{\mathrm{a}}$ & $95 \% \mathrm{CI}^{\mathrm{a}}$ & P-value \\
\hline \multicolumn{6}{|l|}{ Gender } \\
\hline Female & $206(41.6)$ & $230(46.5)$ & 1.00 (reference) & & \\
\hline Male & $289(58.4)$ & $265(53.5)$ & 1.22 & $0.95-1.57$ & $0.125^{\mathrm{a}}$ \\
\hline \multicolumn{6}{|l|}{ Age at recruitment (years) } \\
\hline Mean \pm SD & $57.2 \pm 11.5$ & $55.5 \pm 13.8$ & $1.01^{\mathrm{b}}$ & $1.00-1.02$ & $0.036^{\mathrm{c}}$ \\
\hline Range & $23-89$ & $25-91$ & & & \\
\hline \multicolumn{6}{|l|}{ BMI } \\
\hline Mean \pm SD & $26.6 \pm 4.3$ & $26.7 \pm 4.5$ & 1.00 & $0.96-1.03$ & $0.821^{\mathrm{c}}$ \\
\hline Range & $13.1-44.9$ & $16.6-44.3$ & & & \\
\hline \multicolumn{6}{|l|}{ Smoking status } \\
\hline Never smokers & $243(49.1)$ & $195(39.4)$ & 1.00 (reference) & & \\
\hline Smokers & $74(14.9)$ & $76(15.4)$ & 0.78 & $0.54-1.13$ & $0.193^{\mathrm{a}}$ \\
\hline Ex-smokers $>5$ years & $99(20.0)$ & $76(15.4)$ & 1.05 & $0.73-1.49$ & $0.806^{\mathrm{a}}$ \\
\hline Ex-smokers $\leq 5$ years & $47(9.5)$ & $17(3.4)$ & 2.22 & $1.24-3.99$ & $0.008^{\mathrm{a}}$ \\
\hline Missing & $32(6.5)$ & $131(26.4)$ & 0.20 & $0.13-0.30$ & $<0.001^{\mathrm{a}}$ \\
\hline \multicolumn{6}{|l|}{ Education } \\
\hline Basic & $112(22.6)$ & $89(18.0)$ & 1.00 (reference) & & \\
\hline High school & $174(35.2)$ & $200(40.4)$ & 0.69 & $0.49-0.98$ & $0.036^{\mathrm{a}}$ \\
\hline University & $41(8.3)$ & $72(14.5)$ & 0.45 & $0.28-0.73$ & $0.001^{\mathrm{a}}$ \\
\hline Missing & $168(33.9)$ & $134(27.1)$ & 1.00 & $0.70-1.43$ & $0.984^{\mathrm{a}}$ \\
\hline \multicolumn{6}{|l|}{ Living area } \\
\hline Countryside & $98(19.8)$ & $79(16.0)$ & 1.00 (reference) & & \\
\hline Suburban & $50(10.1)$ & $78(15.8)$ & 0.52 & $0.33-0.82$ & $0.005^{\mathrm{a}}$ \\
\hline Urban & $207(41.8)$ & $212(42.8)$ & 0.79 & $0.55-1.12$ & $0.184^{\mathrm{a}}$ \\
\hline Missing & $140(28.3)$ & $126(25.4)$ & 0.90 & $0.61-1.31$ & $0.572^{\mathrm{a}}$ \\
\hline
\end{tabular}

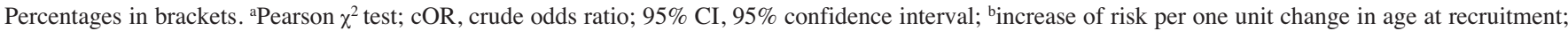
${ }^{\mathrm{c} A N O V A}$ test.

(Applied Biosystems). EPHX1 enzyme activity was inferred according to the results of His113Tyr and Arg139His genotyping (22). For quality control, $10 \%$ of the samples were randomly selected and re-genotyped with $100 \%$ concordance of the results.

Statistical analysis. In the first round of analyses, HardyWeinberg equilibrium was assessed for the control group. The distribution of genotypes did not significantly deviate from equilibrium. The differences in distribution of the genotypes between cases and controls were assessed from $2 \times 2$ tables and Pearson's $\chi^{2}$ test was used to test significance. We further employed binary logistic regression to model the association between the risk of CRC and the studied genotypes and their combinations while adjusting for the effects of the age at recruitment, sex, BMI, smoking, alcohol consumption, living area and education. The two-sided $\mathrm{p}<0.05$ was considered statistically significant. Analyses were performed using Win SPSS v13.0 (SPSS, Chicago, IL). Our study had $85 \%$ power to detect odds ratio (OR) 1.5 at $\alpha=0.05$ for the 0.15 rare allele frequency of $C Y P 1 B 1$ codon 453 (the lowest frequency from the analyzed polymorphisms). The rest of the studied polymorphisms had higher power to detect this OR.

\section{Results}

Characteristics of study population. This case-control study is based on a comparison of 495 CRC cases and 495 controls. Basic characteristics and crude comparison of the cases and controls with respect to the potential confounders are given in Table I. The cases and controls differ significantly in their smoking status, education and living area. Despite the effort to match the controls and cases for age, the controls tend to be slightly younger than the cases (mean difference 1.7 years, $\mathrm{p}=0.036$ ). A biological significance of this age difference is unlikely; nevertheless, when evaluating the effects of studied genotypes and their combinations on the CRC risk, we accounted for age and for effects of the other potential risk factors by means of the binary logistic regression.

Associations of polymorphisms and selected gene combinations with colorectal cancer risk. The summary of crude and adjusted odds ratios (cOR and aOR), 95\% confidence intervals (CI) and corresponding p-values is given in Tables II and III. Carriers of the variant Ser allele in codon 453 of $C Y P 1 B 1$ were at significantly lower risk of CRC than the carriers of the wild-type $(\mathrm{cOR}=0.74,95 \% \mathrm{CI}=0.56-0.96$, 
Table II. Associations of polymorphisms in CYP1B1, EPHX1, NQO1, GSTM1, GSTT1 and GSTP1 with colorectal cancer risk.

\begin{tabular}{|c|c|c|c|c|c|c|c|c|c|}
\hline Gene & Genotype & Cases & Controls & $\mathrm{cOR}^{\mathrm{a}}$ & $95 \% \mathrm{CI}^{\mathrm{a}}$ & $\mathrm{P}$-value ${ }^{\mathrm{a}}$ & $\mathrm{aOR}^{\mathrm{b}}$ & $95 \% \mathrm{CI}^{\mathrm{b}}$ & $\mathrm{P}$-value ${ }^{\mathrm{b}}$ \\
\hline \multirow{5}{*}{$\begin{array}{l}\text { CYP1B1 } \\
\text { codon } 432\end{array}$} & Leu/Leu & $174(35.2)$ & $155(31.3)$ & 1.00 (reference) & & & 1.00 (reference) & & \\
\hline & Leu/Val & $237(47.9)$ & $262(52.9)$ & 0.81 & $0.6-1.07$ & 0.129 & 0.84 & $0.63-1.11$ & 0.222 \\
\hline & $\mathrm{Val} / \mathrm{Val}$ & $84(17.0)$ & $78(15.8)$ & 0.96 & $0.66-1.40$ & 0.829 & 1.04 & $0.70-1.52$ & 0.862 \\
\hline & Leu/Val+Val/ & 321 & 340 & 0.84 & $0.65-1.10$ & 0.200 & 0.88 & $0.67-1.16$ & 0.360 \\
\hline & $q V a l^{\mathrm{c}}$ & 0.41 & 0.42 & & & & & & \\
\hline \multirow{6}{*}{$\begin{array}{l}C Y P 1 B 1 \\
\text { codon } 453\end{array}$} & Asn/Asn & $353(71.3)$ & $320(64.6)$ & 1.00 (reference) & & & 1.00 (reference) & & \\
\hline & Asn/Ser & $134(27.1)$ & 163 (32.9) & 0.75 & $0.57-0.98$ & 0.035 & 0.69 & $0.52-0.91$ & 0.010 \\
\hline & $\mathrm{Ser} / \mathrm{Ser}$ & $8(1.6)$ & $12(2.4)$ & 0.60 & $0.24-1.50$ & 0.277 & 0.52 & $0.21-1.29$ & 0.157 \\
\hline & Asn/Ser+Ser/ & 142 & 175 & 0.74 & $0.56-0.96$ & 0.025 & 0.68 & 0.51-0.89 & 0.006 \\
\hline & Ser & & & & & & & & \\
\hline & $q \mathrm{Ser}^{\mathrm{c}}$ & 0.15 & 0.19 & & & & & & \\
\hline \multirow{3}{*}{$\begin{array}{l}\text { CYP1B1 } \\
\text { diplotype }\end{array}$} & Leu/Leu+Asn/ & 103 & 77 & 1.00 (reference) & & & 1.00 (reference) & & \\
\hline & Asn & & & & & & & & \\
\hline & $\mathrm{Val}+\mathrm{Ser}^{\mathrm{d}}$ & 71 & 97 & 0.55 & $0.36-0.84$ & 0.005 & 0.53 & 0.34-0.83 & 0.005 \\
\hline \multirow{6}{*}{$\begin{array}{l}\text { NQO1 } \\
\text { codon } 187\end{array}$} & Pro/Pro & $346(69.9)$ & $344(69.5)$ & 1.00 (reference) & & & 1.00 (reference) & & \\
\hline & Pro/Ser & $134(27.1)$ & $138(27.9)$ & 0.97 & $0.73-1.28$ & 0.806 & 1.00 & $0.75-1.33$ & 0.997 \\
\hline & $\mathrm{Ser} / \mathrm{Ser}$ & $15(3.0)$ & $13(2.6)$ & 1.15 & $0.54-2.45$ & 0.722 & 1.32 & $0.61-2.85$ & 0.481 \\
\hline & Pro/Ser+Ser/ & 149 & 151 & 0.98 & $0.75-1.29$ & 0.890 & 1.03 & $0.78-1.35$ & 0.853 \\
\hline & Ser & & & & & & & & \\
\hline & $q \mathrm{Ser}^{\mathrm{c}}$ & 0.17 & 0.17 & & & & & & \\
\hline \multirow{2}{*}{$\begin{array}{l}\text { GSTM1 } \\
\text { (deletion) }\end{array}$} & plus & $228(46.1)$ & $254(51.3)$ & 1.00 (reference) & & & 1.00 (reference) & & \\
\hline & null & $267(53.9)$ & $241(48.7)$ & 1.23 & $0.96-1.58$ & 0.098 & 1.30 & $1.01-1.68$ & 0.044 \\
\hline \multirow{2}{*}{$\begin{array}{l}\text { GSTT1 } \\
\text { (deletion) }\end{array}$} & plus & $392(79.2)$ & $395(79.8)$ & 1.00 (reference) & & & 1.00 (reference) & & \\
\hline & null & $103(20.8)$ & $100(20.2)$ & 1.04 & $0.76-1.41$ & 0.813 & 1.07 & $0.78-1.47$ & 0.664 \\
\hline \multirow{6}{*}{$\begin{array}{l}\text { GSTP1 } \\
\text { codon } 105\end{array}$} & Ile/Ile & $223(45.1)$ & $224(45.3)$ & 1.00 (reference) & & & 1.00 (reference) & & \\
\hline & Ile/Val & $229(46.3)$ & $226(45.7)$ & 1.02 & $0.78-1.32$ & 0.895 & 1.01 & $0.77-1.32$ & 0.944 \\
\hline & $\mathrm{Val} / \mathrm{Val}$ & $43(8.7)$ & $45(9.1)$ & 0.96 & $0.61-1.52$ & 0.861 & 1.01 & $0.63-1.61$ & 0.969 \\
\hline & Ile/Val+Vall & 272 & 271 & 1.01 & $0.79-1.30$ & 0.949 & 1.01 & $0.78-1.30$ & 0.942 \\
\hline & Val & & & & & & & & \\
\hline & $q \mathrm{Val}^{\mathrm{c}}$ & 0.32 & 0.32 & & & & & & \\
\hline \multirow{6}{*}{$\begin{array}{l}\text { EPHX1 } \\
\text { codon } 113\end{array}$} & Tyr/Tyr & $221(44.6)$ & $231(46.7)$ & 1.00 (reference) & & & 1.00 (reference) & & \\
\hline & $\mathrm{T} y r / H i s$ & $224(45.3)$ & $212(42.8)$ & 1.10 & $0.85-1.44$ & 0.460 & 1.09 & $0.83-1.43$ & 0.534 \\
\hline & His/His & $50(10.1)$ & $52(10.5)$ & 1.01 & $0.65-1.55$ & 0.982 & 0.96 & $0.62-1.49$ & 0.869 \\
\hline & Tyr/His + His/ & 274 & 264 & 1.09 & $0.85-1.39$ & 0.523 & 1.06 & $0.82-1.37$ & 0.635 \\
\hline & His & & & & & & & & \\
\hline & $q H i s^{\mathrm{c}}$ & 0.33 & 0.32 & & & & & & \\
\hline \multirow{6}{*}{$\begin{array}{l}\text { EPHX1 } \\
\text { codon } 139\end{array}$} & His/His & $297(60.0)$ & $290(58.6)$ & 1.00 (reference) & & & 1.00 (reference) & & \\
\hline & His/Arg & $173(34.9)$ & $183(37.0)$ & 0.92 & $0.71-1.20$ & 0.551 & 0.89 & $0.68-1.17$ & 0.411 \\
\hline & Arg/Arg & $25(5.1)$ & $22(4.4)$ & 1.11 & $0.61-2.01$ & 0.732 & 1.06 & $0.58-1.96$ & 0.845 \\
\hline & His/Arg+Arg/ & 198 & 205 & 0.94 & $0.73-1.22$ & 0.651 & 0.91 & $0.70-1.18$ & 0.482 \\
\hline & Arg & & & & & & & & \\
\hline & $q A r g^{\mathrm{c}}$ & 0.23 & 0.23 & & & & & & \\
\hline
\end{tabular}

Number of genotype carriers presented (percentages in brackets). ${ }^{\mathrm{a} C r u d e}$ odds ratios (cOR) and $95 \%$ confidence intervals (95\% CI); ${ }^{\mathrm{b}} \mathrm{Odds}$ ratios (aOR) and $95 \%$ confidence intervals $(95 \% \mathrm{CI}$ ) adjusted for age at diagnosis, gender, smoking, education and living area; cfrequency of variant allele carriage in studied subgroups; ${ }^{\mathrm{d}}$ carriers of at least one variant allele in codons 432 and 453. 
Table III. Associations of combinations of polymorphisms in EPHX1, GSTM1, GSTT1 and GSTP1 with colorectal cancer risk.

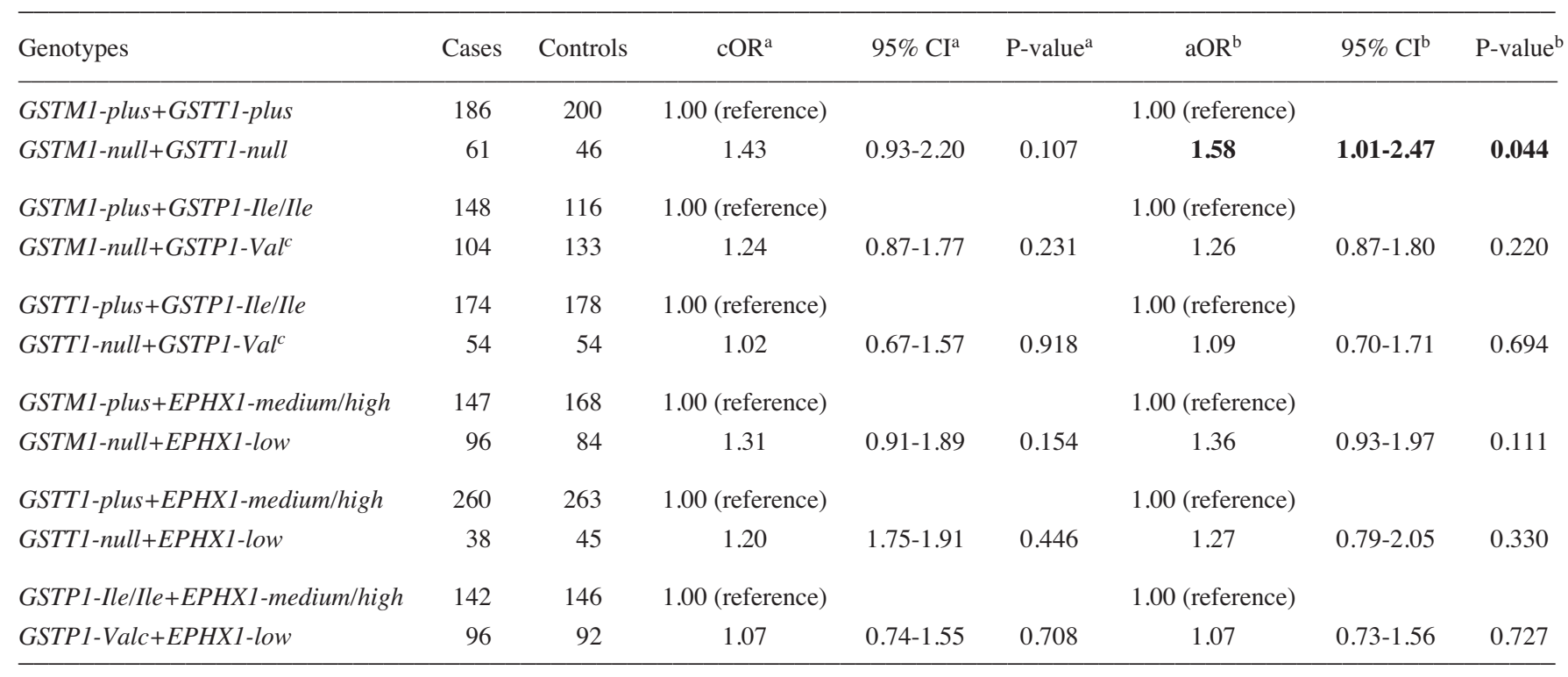

Number of genotype carriers presented. ${ }^{\mathrm{a} C r u d e}$ odds ratios (cOR) and 95\% confidence intervals (95\% CI); bodds ratios (aOR) and 95\% confidence intervals $(95 \% \mathrm{CI})$ adjusted for age at diagnosis, gender, smoking, education and living area; ${ }^{\mathrm{c}}$ carriers of at least one variant allele, i.e. genotypes Ile/Val or Val/Val in GSTP1.

$\mathrm{p}=0.025$, Table II). The protective effect was more apparent, when the carriers of the wild-type genotype in both codons 432 and 453 of $C Y P 1 B 1$ were combined and compared to carriers of the variant alleles in these codons $(\mathrm{cOR}=0.55,95 \%$ $\mathrm{CI}=0.36-0.84, \mathrm{p}=0.005$, Table II). The adjusted analyses of the polymorphism in codon 453 of $C Y P 1 B 1$ and the codon 432-453 diplotype also showed significant associations with $\mathrm{CRC}$ risk $(\mathrm{aOR}=0.68,95 \% \mathrm{CI}=0.51-0.89, \mathrm{p}=0.006$ and $\mathrm{aOR}=0.53,95 \% \mathrm{CI}=0.34-0.83, \mathrm{p}=0.005$, respectively, Table II). The deletion of GSTMI was associated with a moderate increase in the $\mathrm{CRC}$ risk $(\mathrm{cOR}=1.23,95 \% \mathrm{CI}=0.96-1.58$, $\mathrm{p}=0.098$, Table II). This association reached the level of statistical significance after adjustment $(\mathrm{aOR}=1.30,95 \%$ $\mathrm{CI}=1.01-1.68, \mathrm{p}=0.044$, Table II). Neither genetic polymorphisms in EPHX1, NQO1, GSTP1 and GSTT1 nor the inferred EPHX1 activity modified CRC risk (results not shown). In agreement with our previous studies $(19,22)$, the effect of functionally-relevant combinations of polymorphisms in GSTs and EPHX1 was also analyzed. Of the analyzed combinations (GSTM1-GSTT1, GSTM1-GSTP1, GSTT1GSTP1, GSTM1-EPHX1-activity, GSTT1-EPHX1-activity, and GSTP1-EPHX1-activity), none were significantly associated with the CRC risk in crude analyses (Table III). However, adjusted analyses showed a significantly higher risk in individuals carrying the combination of GSTM1-null and GSTT1-null genotype when compared to GSTM1-plus and GSTT 1-plus carriers (aOR $=1.58,95 \% \mathrm{CI}=1.01-2.47$, $\mathrm{p}=0.044$, Table III). Smoking did not modify the observed effects of any studied polymorphisms (results not shown).

\section{Discussion}

The Czech Republic has one of the highest CRC incidences worldwide. Possible factors contributing to the high CRC incidence in the Czech Republic may involve dietary habits, e.g. high content of fat containing diet based on fried and roasted pork meat (24), relatively homogeneous genetic background (25), and a good capture of CRC cases due to well established cancer registry.

The major purpose for defining genetic markers associated with cancer disease is to target preventive screening programs to high-risk individuals (FOBT, colonoscopy or flexible sigmoidoscopy in CRC) and interventions to prevent the development of cancer (dietary changes, cessation of smoking, avoidance of obesity). The study of association of XME polymorphisms with cancer needs to be controlled very carefully in terms of exposure, age and gender of participants $(23,26)$. This was our primary focus during the statistical analyses. Most of the variables (age, gender, BMI and smoking) included in our statistical analyses as potential confounders are so-called obligatory confounders in the field of cancer epidemiology (27-29). Education was included as a surrogate measure for socio-economic status of study participants, which is also considered to be potentially important confounder. The living area (urban vs. rural) was selected as a surrogate measure of some features of lifestyle and environmental exposures. In the Czech Republic, both living area and education are commonly used for this purpose (30). We have used the colonoscopy-negative control group to ensure disease-free control individuals, as a negative colonoscopy result serves as the best available proof of the absence of CRC (31).

Variant allele frequencies of the studied XME polymorphisms in the control group did not significantly differ from previously published data from the Czech population $(22,23)$. Polymorphisms in EPHXI (neither single polymorphisms nor their combinations which serve for enzyme activity deduction), GSTP1 and NQO1 did not modify CRC risk. The results 
obtained in this study correspond to some previous studies [EPHX1, negative results $(11,12,15)]$ but do not confirm findings published by others [EPHX] as a CRC protective factor; (32) and NQO1 as a CRC risk factor $(12,14,33)]$. It is generally true that population-specific genetics and/or lifestyle differences together with variations in study design, study power and methodology may cause discrepancies among case-control studies. It is essential to reproduce results on adequate samples sizes from ethnically well-defined populations.

In our study, GSTM1-null genotype increased the CRC risk 1.3-fold alone and 1.6-fold in combination with the inheritance of GSTT1-null genotype. Similarly to our study, GSTM1-null and GSTT1-null genotypes were identified as $\mathrm{CRC}$ risk factors $(\mathrm{OR}=1.62, \mathrm{CI}=1.06-2.46$ and $\mathrm{OR}=1.64$, $\mathrm{OR}=1.10-2.59$, respectively) in the Turkish population (34). The combination of polymorphism in GSTP1 with GSTM1null was associated with higher CRC risk in a Japanese study (35). Elevation in CRC risk by inheritance of the GSTM1null allele $(\mathrm{OR}=1.41)$ was also observed amongst UK CRC patients, although this effect did not reach statistical significance (36). However, no association of GSTM1 or GSTT1 with CRC risk was observed in the Scottish population (37). The combination of GSTM1 and GSTT1 deletions was associated with higher risk of developing a transverse or rectal tumor (34). Functional study on 208 German individuals, who underwent colonoscopy, observed significant decrease in GST activity, GSH levels and GSTP1 expression from proximal to distant colon (38). Moreover, GSTP1 seems highly relevant for CRC therapy as the GSTP1 polymorphism in codon 105 was associated in a dose-dependent fashion with increased survival of patients with advanced CRC receiving 5-FU/ oxaliplatin chemotherapy (39). Thus, in addition to the relevance for predictive testing, there may be a role of variants in XME genes as predictive therapeutic markers.

A study of Huang et al (40) on African Americans and American Caucasians found that GSTT1 and GSTM1 polymorphisms may be slightly related to the CRC risk and that there may be ethnic differences in gene-smoking interactions. However, our study in the Czech population did not find any modifying effect of smoking. According to the study of Skjelbred et al (41), GSTM1, GSTP1 and EPHX1 may modify the effect of dietary factors on the risk of developing CRC and colorectal adenoma. Moore et al (18) published the association between advanced villous colorectal adenomas (precursors of CRC) and GSTM1-plus and GSTT1-null in smokers. A recent meta-analysis supports the role of GSTM1null as a potential CRC risk factor, especially in Caucasian populations (42). Published results along with our data suggest that colorectal carcinogenesis may be partly driven by interaction between XME and environmental factors. The exact nature of these interactions needs to be studied in detail. Moreover, various populations and subpopulations might have a higher CRC risk and the underlying mechanisms may differ.

Carriers of the variant allele in codon 453 of $C Y P 1 B 1$ (rs1800440) indicated a lower CRC risk. Analysis of the CYP1B1 diplotype further underlined this effect. Our study adds additional information to recently reported observations. CYPIB1 was found to be a CRC risk associated gene by
Bethke et al (43). Fan et al (44) suggested a significant interaction between $C Y P 1 B 1$ and cigarette smoking in a CRC case-only study in the Chinese population. Furthermore, the association between CRC risk and polymorphisms in CYP1B1 (and also CYP1A1 and CYP1A2) was observed in the case-control study of Landi et al (45). Although we identified the rs 1800440 polymorphism in CYP1B1 as a potential CRC risk-associated allele, the two previously published studies did not associate this SNP with CRC risk $(43,45)$. Conflicting results of these case-control studies may be due to unknown interactions with environmental or other genetic factors and may vary according to the choice of polymorphisms to be genotyped. Bandiera et al (46) demonstrated that $\mathrm{P} 450$ 1B1-Ser453 protein displays lower intracellular protein levels and is degraded more rapidly than the other P450 1B1 variants. They concluded that it is probable that individuals with the $C Y P 1 B 1$-Ser453 allele have reduced metabolic activation of some endogenous (e.g. estrogens) and exogenous (e.g. PAHs or heterocyclic amines) carcinogens. Indeed, carriers of the variant $C Y P 1 B 1$ Ser/Ser genotype in codon 453 showed a significantly reduced incidence of endometrial cancer compared with homozygotes who carried Asn at this position $(\mathrm{OR}=0.62 ; 95 \% \mathrm{CI}=0.43-0.91)$ (47).

In conclusion, our study identified polymorphisms in CYP1B1, GSTM1 and GSTT1 as modifiers of CRC risk in the Czech population. If verified by independent studies, these polymorphisms might be used for identification of high-risk individuals. Preventive screening programs and interventions to prevent the development of CRC could then be targeted to these individuals.

\section{Acknowledgements}

The authors are grateful to Simona Susova, Ing from the National Institute of Public Health, Prague Czech Republic, for taking part in genotyping analyses. The study was supported by grants of the Internal Grant Agency of the Czech Ministry of Health, no. IGA 10230-3, the Czech Science Foundation no. GACR 310/07/1430 and the Grant Agency of Charles University no. GAUK 15109/2009.

\section{References}

1. Kamangar F, Dores GM and Anderson WF: Patterns of cancer incidence, mortality, and prevalence across five continents: defining priorities to reduce cancer disparities in different geographic regions of the world. J Clin Oncol 24: 2137-2150, 2006.

2. Ferlay J, Autier P, Boniol M, Heanue M, Colombet M and Boyle P: Estimates of the cancer incidence and mortality in Europe in 2006. Ann Oncol 18: 581-592, 2007.

3. Cancer Incidence 2005 in the Czech Republic. IHIS CR, NOR CR, Czech Republic, pp30-33, 2008.

4. Rustgi AK: The genetics of hereditary colon cancer. Genes Dev 21: 2525-2538, 2007.

5. Norat T, Bingham S, Ferrari P, et al: Meat, fish, and colorectal cancer risk: the European Prospective Investigation into cancer and nutrition. J Natl Cancer Indy 97: 906-916, 2005.

6. Liang PS, Chen TY and Giovannucci E: Cigarette smoking and colorectal cancer incidence and mortality: systematic review and meta-analysis. Int J Cancer 124: 2406-2415, 2009.

7. Soucek P: Xenobiotics. In: Encyclopedia of Cancer. Schwab M (ed). 2nd edition. Springer-Verlag, New York, 2008.

8. Boursi B and Arber N: Current and future clinical strategies in colon cancer prevention and the emerging role of chemoprevention. Curr Pharm Des 13: 2274-2282, 2007. 
9. Küry S, Buecher B, Robiou-du-Pont S, et al: Combinations of cytochrome $\mathrm{P} 450$ polymorphisms enhancing the risk for sporadic colorectal cancer related to red meat consumption. Cancer Epidemiol Biomarkers Prev 16: 1460-1467, 2007.

10. Hassett C, Aicher L, Sidhu JS and Omiecinski CJ: Human microsomal epoxide hydrolase: genetic polymorphism and functional expression in vitro of amino acid variants. Hum Mol Genet 3: 421-428, 1994.

11. Robien K, Boynton A and Ulrich CM: Pharmacogenetics of folate-related drug targets in cancer treatment. Pharmacogenomics 6: 673-689, 2005.

12. Van der Logt EM, Bergevoet SM, Roelofs HM, et al: Role of epoxide hydrolase, NADP;H:quinone oxidoreductase, cytochrome P450 2E1 or alcohol dehydrogenase genotypes in susceptibility to colorectal cancer. Mutat Res 593: 39-49, 2006.

13. Traver RD, Siegel D, Beall HD, Phillips RM, Gibson NW, Franklin WA and Ross D: Characterization of a polymorphism in NADP(H):quinone oxidoreductase DT-diaphorase. Br J Cancer 75: 69-75, 1997

14. Begleiter A, Hewitt D, Maksymiuk AW, Ross DA and Bird RP. A NADP;H:quinone oxidoreductase 1 polymorphism is a risk factor for human colon cancer. Cancer Epidemiol Biomarkers Prev 15: 2422-2426, 2006.

15. Mitrou PN, Watson MA, Loktionov AS, et al: Role of NQO1C609T and EPHX1 gene polymorphisms in the association of smoking and alcohol with sporadic distal colorectal adenomas: results from the UKFSS Study. Carcinogenesis 28: 875-882, 2007

16. Zimniak $\mathrm{P}$, Nanduri B, Pikula $\mathrm{S}$, et al: Naturally occuring human glutathione S-transferase GSTP1-1 isoforms with isoleucine and valine in position 104 differ in enzymic properties. Eur Biochem 224: 893-899, 1994

17. Ferraz JM, Zinzindohoué F, Lecomte T, et al: Impact of GSTT1, GSTM1, GSTP1 and NAT2 genotypes on KRAS2 and TP53 gene mutations in colorectal cancer. Int J Cancer 110: 183-187, 2004

18. Moore LE, Huang WY, Chatterjee N, et al: GSTM1, GSTT1, and GSTP1 polymorphisms and risk of advanced colorectal adenoma. Cancer Epidemiol Biomarkers Prev 14: 1823-1827, 2005.

19. Naccarati A, Soucek P, Stetina R, et al: Genetic polymorphisms and possible gene-gene interactions in metabolic and DNA repair genes: effects on DNA damage. Mutat Res 593: 22-31, 2006.

20. Vasen HF, Watson P, Mecklin JP and Lynch HT: New clinical criteria for hereditary non-polyposis colorectal cancer (HNPCC, Lynch syndrome) proposed by the International Collaborative group on HNPCC. Gastroenterology 116: 1453-1456, 1999.

21. Landi S, Gemignani F, Naccarati A, et al: Polymorphisms within micro-RNA-binding sites and risk of sporadic colorectal cancer. Carcinogenesis 29: 579-584, 2008.

22. Sarmanova J, Susova S, Gut I, et al: Breast cancer: role of polymorphisms in biotransformation enzymes. Eur J Hum Genet 12 : 848-854, 2004

23. Vrana D, Pikhart H, Mohelnikova-Duchonova B, et al: The association between Glutathione S-transferase Gene polymorphisms and pancreatic cancer in central European Slavonic population. Mutat Res 680: 78-81, 2009.

24. Dofkova M, Kopriva V, Resova D, Rehurkova I and Ruprich J: The development of food consumption in the Czech Republic after 1989. Public Health Nutr 4: 999-1003, 2001.

25. Heath SC, Gut IG, Brennan P, et al: Investigation of the fine structure of European populations with applications to disease association studies. Eur J Hum Genet 16: 1413-1429, 2008

26. Mohelnikova-Duchonova B, Vrana D, Holcatova I, Ryska M, Smerhovsky Z and Soucek P: CYP2A13, ADH1B and ADH1C gene polymorphisms and pancreatic cancer risk. Pancreas 39: 144-148, 2010

27. McFadden E, Luben R, Wareham N, Bingham S and Khaw KT: Occupational social class, educational level, smoking and body mass index, and cause-specific mortality in men and women: a prospective study in the European Prospective Investigation of Cancer and Nutrition in Norfolk (EPIC-Norfolk) cohort. Eur J Epidemiol 23: 511-522, 2008

28. Sengupta N, Gill KA, MacFie TS, Lai CS, Suraweera N, Mcdonald S and Silver A: Management of colorectal cancer: a role for genetics in prevention and treatment? Pathol Res Pract 204: 469-477, 2008

29. Harriss DJ, Atkinson G, George K, et al: Lifestyle factors and colorectal cancer risk (1): systematic review and meta-analysis of associations with body mass index. Colorectal Dis 11 : $547-563,2009$
30. Zejglicová K, Kratenová J, Maly M and Kubínová R: Incidence of risk factors of chronic non-infectious diseases including socio-economic factors in the urban middle age population in the Czech Republic-results of HELEN study. Cas Lek Cesk 145: 936-942, 2006.

31. Singh H, Turner D, Xue L, Targownik LE and Bernstein CN: Risk of developing colorectal cancer following a negative colonoscopy examination: evidence for a 10-year interval between colonoscopies. JAMA 295: 2366-2373, 2006.

32. Sachse C, Smith G, Wilkie MJ, et al: A pharmacogenetic study to investigate the role of dietary carcinogens in the etiology of colorectal cancer. Carcinogenesis 23: 1839-1849, 2002.

33. Chao C, Zhang ZF, Berthiller J, Boffetta P and Hashibe M: NAD(P)H:quinone oxidoreductase 1 NQO1 Pro187Ser polymorphism and the risk of lung, bladder, and colorectal cancers: a meta-analysis. Cancer Epidemiol Biomarkers Prev 15: 979-987, 2006.

34. Ates NA, Tamer L, Ates C, Ercan B, Elipek T, Ocal K and Camdeviren H: Glutathione S-transferase M1, T1, P1 genotypes and risk for development of colorectal cancer. Biochem Genet 43: 149-163, 2005.

35. Yoshioka M, Katoh T, Nakano M, Takasawa S, Nagata N and Itoh H: Glutathione S-transferase (GST) M1, T1, P1, Nacetyltransferase (NAT) 1 and 2 genetic polymorphisms and susceptibility to colorectal cancer. J UOEH 21: 133-147, 1999.

36. Ye Z and Parry JM: Genetic polymorphisms in the cytochrome P450 1A1, glutathione S-transferase M1 and T1, and susceptibility to colon cancer. Teratog Carcinog Mutagen 22: 385-392, 2002.

37. Little J, Sharp L, Masson LF, Brockton NT, Cotton SC Haites NE and Cassidy J: Colorectal cancer and genetic polymorphisms of CYP1A1, GSTM1 and GSTT1: a case-control study in the Grampian region of Scotland. Int J Cancer 119: 2155-2164, 2006

38. Hoensch H, Peters WH, Roelofs HM and Kirch W: Expression of the glutathione enzyme system of human colon mucosa by localisation, gender and age. Curr Med Res Opin 22: 1075-1083, 2006.

39. Stoehlmacher J, Park DJ, Zhang W, Groshen S, Tsao-Wei DD, $\mathrm{Yu} \mathrm{MC}$ and Lenz HJ: Association between glutathione Stransferase P1, T1, and M1 genetic polymorphism and survival of patients with metastatic colorectal cancer. J Natl Cancer Inst 94: 936-942, 2002.

40. Huang K, Sandler RS, Millikan RC, Schroeder JC, North KE and $\mathrm{Hu}$ J: GSTM1 and GSTT1 polymorphisms, cigarette smoking, and risk of colon cancer: a population-based casecontrol study in North Carolina (United States). Cancer Causes Control 17: 385-394, 2006.

41. Skjelbred CF, Saebø M, Hjartåker A, et al: Meat, vegetables and genetic polymorphisms and the risk of colorectal carcinomas and adenomas. BMC Cancer 7: 228, 2007.

42. Gao Y, Cao Y, Tan A, Liao C, Mo Z and Gao F: Glutathione Stransferase M1 polymorphism and sporadic colorectal cancer risk: an updating meta-analysis and HuGE review of 36 casecontrol studies. Ann Epidemiol 20: 108-121, 2010.

43. Bethke L, Webb E, Sellick G, et al: Polymorphisms in the cytochrome P450 genes CYP1A2, CYP1B1, CYP3A4, CYP3A5, CYP11A1, CYP17A1, CYP19A1 and colorectal cancer risk. BMC Cancer 7: 123, 2007.

44. Fan C, Jin M, Chen K, Zhang Y, Zhang S and Liu B: Case-only study of interactions between metabolic enzymes and smoking in colorectal cancer. BMC Cancer 7: 115, 2007.

45. Landi S, Gemignani F, Moreno V, et al: A comprehensive analysis of phase I and phase II metabolism gene polymorphisms and risk of colorectal cancer. Pharmacogenet Genomics 15: 535-546, 2005

46. Bandiera S, Weidlich S, Harth V, Broede P, Ko Y and Friedberg T: Proteasomal degradation of human CYP1B1: effect of the Asn453Ser polymorphism on the post-translational regulation of CYP1B1 expression. Mol Pharmacol 67: 435-443, 2005.

47. McGrath M, Hankinson SE, Arbeitman L, Colditz GA Hunter DJ and De Vivo I: Cytochrome P450 1B1 and catecholO-methyltransferase polymorphisms and endometrial cancer susceptibility. Carcinogenesis 25: 559-565, 2004. 